\title{
ESTUDO ANATÔMICO DA MADEIRA DE HANDROANTHUS PULCHERRIMUS (SANDWITH) S. GROSE ${ }^{1}$
}

\author{
JOSÉ NEWTON CARDOSO MARCHIORI ${ }^{2}$
}

\section{RESUMO}

A madeira de Handroanthus pulcherrimus (Sandwith) S. Grose é microscopicamente descrita e ilustrada. Foram observados os seguintes caracteres anatômicos: estrutura estratificada completa, placa de perfuração simples, pontoações intervasculares alternas, raios homocelulares uni a trisseriados, fibras libriformes e parênquima paratraqueal aliforme, em curtos segmentos tangenciais e em estreita linha marginal.

Palavras-chave: Handroanthus pulcherrimus, Tabebuia pulcherrima, anatomia da madeira, Bignoniaceae.

\section{SUMMARY}

[Wood anatomy of Handroanthus pulcherrimus (Sandwith) S. Grose].

The wood of Handroanthus pulcherrimus (Sandwith) S. Grose is anatomically described and illustrated. The following anatomical features were observed: ripple marks, simple perforation plates, alternate intervascular pitting, homogeneous rays with 1 to 3 cells wide, libriform fibers and aliform paratracheal parenchyma, in short tangential segments and marginal lines.

Key words: Handroanthus pulcherrimus, Tabebuia pulcherrima, wood anatomy, Bignoniaceae.

\section{INTRODUÇÃO}

Descrita como Tabebuia pulcherrima Sandwith, com base em material coletado na Argentina $^{3}$, o ipê-amarelo do Alto Uruguai tem distribuição restrita ao sul do Brasil, leste do Paraguai e províncias adjacentes de Corrientes e Misiones (Zapater et al., 1009). Na proposi-

Recebido em 13-1-2009 e aceito para publicação em 06-3-2009.

${ }^{2}$ Engenheiro Florestal, Dr, Professor Titular do Departamento de Ciências Florestais, Universidade Federal de Santa Maria, RS. Bolsista de Produtividade em Pesquisa, CNPq - Brasil. Balduinia @mail.ufsm.br

3 O typus (Bertoni 2937), conservado no Herbário de Kew (Inglaterra), é procedente de Acaragua, Dep. San Javier (Misiones). Coletado em 18-9-1946, consta, na etiqueta, a altitude do ponto de coleta $(200 \mathrm{~m})$ e a seguinte referência: "árbol alto, 15-20 m, fl. amarilla" (Sandwith, 1948. Op. cit., p. 134). Das amostras brasileiras, referidas na descrição da espécie, cabe destacar uma coleta de James Tweedie no rio "Jacquary", não longe, portanto, do local de procedência da madeira utilizada no presente trabalho; na etiqueta deste material, o viajante inglês anotou: "one of the great ornaments of the forest, it is a large tree and is frequently covered with large yellow flowers succeeded with seed pods hanging down in bunches 10 inches long" (Sandwith, 1948. Op. cit. p. 135). ção do gênero Handroanthus, Mattos (1970) não incluiu a espécie em estudo, de modo que somente com os estudos de sistemática molecular, que reconheceu três clados no antigo gênero Tabebuia (Grose \& Olmestead, 2007), é que o material em estudo passou a figurar na literatura botânica como Handroanthus pulcherrimus (Sandwith) S. Grose, binômio atualmente válido.

Por suas flores amarelas, Handroanthus pulcherrimus separa-se facilmente do ipê-roxo (Handroanthus heptaphyllus), integrante da mesma tipologia de vegetação (Floresta Estacional do Alto Uruguai). Comparada a Handroanthus umbellatus e $H$. chrysotrichus, que também possuem flores amarelas, o material em estudo distingue-se por ter folíolos brancos ou branco-amarelados, com denso tomento de pelos ramificados. De Handroanthus albus, espécie que compartilha deste último aspecto morfológico, $H$. pulcherrimus separa-se pelas folhas menores, comumente 5-folioladas (5-7folioladas em $H$. albus), bem como pelas cápsulas estreitas $(<1,5 \mathrm{~cm})$, com sementes de até $5 \mathrm{~mm}$ de comprimento (Sandwith \& Hunt, 1974). 
Ainda desconhecida, sob o ponto de vista anatômico, a presente pesquisa visa à descrição microscópica da madeira de Handroanthus pulcherrimus, contribuindo, desta forma, para o conhecimento das Bignoniáceas euxilóforas sul-brasileiras.

\section{MATERIAL E MÉTODOS}

Coletado na localidade de Gruta da Linha 1, no interior do município de Nova Esperança do Sul - RS, o material em estudo consiste de uma amostra de madeira e respectivo material botânico, anexados ao Herbário do Departamento de Ciências Florestais (HDCF) da Universidade Federal de Santa Maria, sob o número 190.

Para a descrição da madeira, foram preparadas lâminas de cortes anatômicos e de macerado. $\mathrm{Da}$ amostra de madeira, coletada do tronco e à altura do peito, foram extraídos três corpos-deprova $(1 \times 2 \times 3 \mathrm{~cm})$ da parte mais externa do lenho, orientados para a obtenção de cortes nos planos transversal, longitudinal radial e longitudinal tangencial. Um outro bloquinho foi também retirado, com vistas à maceração.

Os corpos-de-prova foram amolecidos por fervura em água e seccionados em micrótomo de deslizamento, regulado para a obtenção de cortes com espessura nominal de $20 \mu \mathrm{m}$. Usouse coloração com acridina-vermelha, crisoidina e azul-de-astra (Dujardin, 1964), desidratação em série alcoólica ascendente $(30 \%, 50 \%, 75 \%$, $90 \%, 95 \%$ e duas vezes álcool absoluto), diafanização em xilol e montagem de lâminas permanentes, com Entellan. Na maceração, seguiu-se o método de Jeffrey (Burger \& Richter, 1991).

A descrição microscópica da madeira baseou-se em Ibama (1992). As medições foram realizadas em microscópio binocular dotado de ocular com escala graduada, no Laboratório de Anatomia da Madeira, da Universidade Federal de Santa Maria. Os dados quantitativos, constantes na descrição, correspondem aos valores mínimo, médio e máximo, respectivamente, seguido do desvio padrão (s). As fotomicrografias foram realizadas na Universidade Federal do
Paraná, em aparelho Olympus cx40, equipado com câmera digital Olympus Camedia c3000.

\section{DESCRIÇÃO ANATÔMICA}

Anéis de crescimento: distintos, marcados, fracamente, por zona fibrosa tangencial mais escura e por estreito parênquima marginal.

Vasos: de seção arredondada (43 - 56 - 77 $\mu \mathrm{m} ; \mathrm{s}=7,69$ ), em porosidade difusa, uniforme, com frequência de $7-14-24 / \mathrm{mm}^{2}$; são principalmente solitários, menos comumente em múltiplos radiais de $2-5$ e em cachos de poucas unidades. Elementos vasculares de $200-258-$ $350 \mu \mathrm{m}$ de comprimento $(\mathrm{s}=28,32)$, com placas de perfuração simples, oblíquas; apêndices ausentes ou então curtos, em uma, menos comumente em ambas as extremidades. Espessamentos helicoidais, estriações e tilos, ausentes. Pontoações intervasculares alternas, arredondadas $(8-9,5-11 \mu \mathrm{m} ; \mathrm{s}=0,80)$ e não ornamentadas, com abertura lenticular, horizontal, inclusa. Pontoações raio-vasculares e parênquimo-vasculares, semelhantes às intervasculares, embora menores. Conteúdo amarelado, abundante em vasos.

Parênquima axial: paratraqueal aliforme, com finas expansões tangenciais que confluem em segmentos mais longos, sem formar, todavia, faixas tangenciais contínuas; parênquima marginal, em estreita linha. Células parenquimáticas em séries de 2 , menos comumente 3 células; séries de 206-226-293 $\mu \mathrm{m}$ de altura $(\mathrm{s}=24,06)$ e $14-22-28 \mu \mathrm{m}$ de largura $(\mathrm{s}=3,52)$.

Raios: homocelulares, compostos inteiramente de células procumbentes, com frequiência de $11-12,5-17 / \mathrm{mm}(\mathrm{s}=1,55)$; células perfuradas, eretas, quadradas, latericuliformes, envolventes, oleíferas e cristalíferas, ausentes. Raios unisseriados, escassos (9\%); de 24-84$151 \mu \mathrm{m}$ de altura $(\mathrm{s}=34,32)$, com $1-5-9$ células ( $\mathrm{s}=2,04)$, e $7-12-22 \mu \mathrm{m}$ de largura ( $\mathrm{s}$ $=4,74)$. Os multisseriados, em sua maioria bisseriados $(78 \%)$, menos comumente trisseriados (13\%); medem $62-119-180 \mu \mathrm{m}$ de altura $(\mathrm{s}=23,29)$, com $2-7-10$ células $(\mathrm{s}=$ 

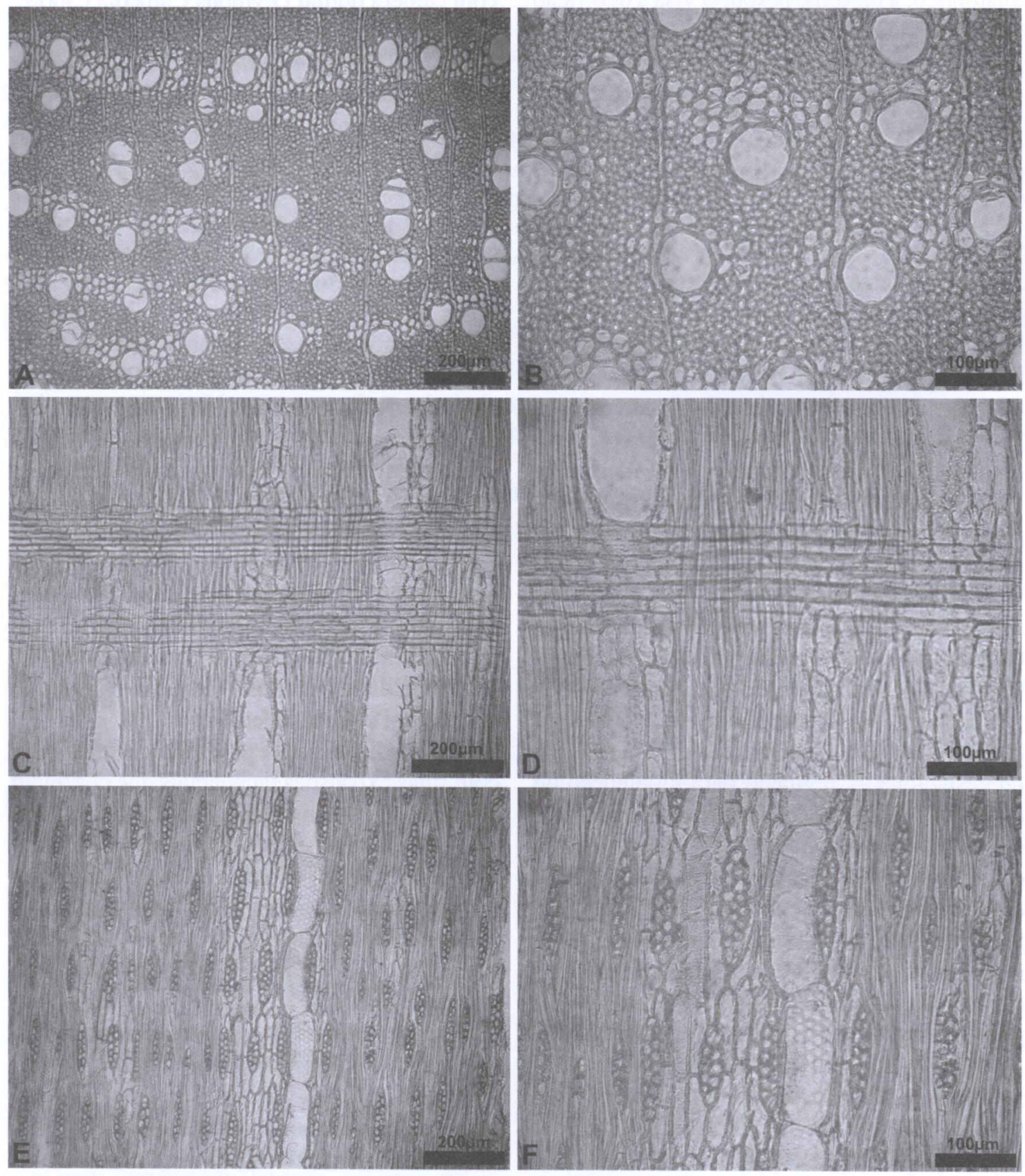

FIGURA 1 - Aspectos anatômicos da madeira de Handroanthus pulcherrimus. A, B - Porosidade difusa, vasos solitários e em curtos múltiplos radiais, raios finos, fibras de paredes espessas e parênquima paratraqueal aliforme-confluente, compondo segmentos tangenciais de extensão variada, além de parênquima marginal (seção transversal). C, D - Raios homocelulares, vasos com parênquima paratraqueal seriado e fibras de paredes espessas (seção longitudinal radial). E, F - Estrutura estratificada completa, parênquima axial em séries de 2, menos comumente 3 células, e pontoações intervasculares alternas (seção longitudinal tangencial). 
$1,58)$, e $10-22-31 \mu \mathrm{m}$ de largura $(\mathrm{s}=4,52)$. Raios agregados e fusionados, ausentes.

Fibras: libriformes, com pontoações simples pequenas, mais abundantes nas faces radiais da parede; são muito curtas até curtas (780 - 900 $1100 \mu \mathrm{m} ; \mathrm{s}=42,68)$ e de paredes espessas a muito espessas $(5-6 \mu \mathrm{m})$.

Outros caracteres: madeira de estratificação completa em plano tangencial, incluindo raios, parênquima axial, elementos vasculares e fibras. Canais intercelulares, canais celulares, cistos glandulares, cristais, sílica, floema incluso, células oleíferas, células mucilaginosas e máculas medulares, ausentes.

\section{ANÁLISE DA ESTRUTURA ANATÔMICA}

A presença de porosidadie difusa, com vasos desprovidos de espessamentos espiralados e pontoações não ornamentadas, bem como os raios relativamente estreitos e baixos, inserem a madeira na família Bignoniaceae, de acordo com chave dicotômica de Record (1943), para madeiras neotropicais com estrutura estratificada.

A predominância de raios bisseriados com menos de 10 células de altura e escassos trisseriados, a abundância de conteúdo amarelado em vasos, bem como o parênquima nos padrões paratraqueal aliforme e marginal, permitem a inclusão da espécie no "grupo Lapacho" do gênero Tabebuia, segundo Record \& Hess $(1940,1943)$. Cabe ressaltar que o referido grupo infragenérico, transferido ao gênero Handroanthus (Mattos, 1970), apresenta outra espécie nativa na Floresta Estacional do Alto Uruguai: Handroanthus heptaphyllus (Vell.) Mattos (Lozano \& Zapater, 2008), conhecida regionalmente como ipê-roxo. Comparada a esta espécie, a madeira presentemente descrita separa-se pela predominância de raios bisseriados, com escassos trisseriados, pelos vasos mais estreitos (diâmetro $<80 \mu \mathrm{m}$ ) e pelo parênquima paratraqueal aliforme relativamente abundante, compondo segmentos tangenciais mais longos, por vezes confluentes.

\section{REFERÊNCIAS BIBLIOGRÁFICAS}

BURGER, L.M.; RICHTER, H.G. Anatomia da madeira. São Paulo: Ed. Nobel, 1991. 154 p.

DUJARDIN, E.P. Eine neue Holz-Zellulosenfaerbung. Mikrokosmos, n. 53, p. 94, 1964.

GROSE, S.O.; OLMESTEAD, R.G. Taxonomic revision in the polyphyletic genus Tabebuia s.1. (Bignoniaceae). Syst. Bot., v. 32, n. 3, p. 660670, 2007.

IBAMA, Instituto Brasileiro do Meio Ambiente e dos Recursos Naturais Renováveis. Diretoria de Incentivo à Pesquisa e Divulgação. Laboratório de Produtos Florestais. Normas e procedimentos em estudos de Anatomia da Madeira: I Angiospermae, II - Gymnospermae. Brasília, 1992. 17 p. (Ser. Tecn. n. 15).

LOZANO, E.C.; ZAPATER, M.A. Delimitación y estatus de Handroanthus heptaphyllus y Handroanthus impetiginosus (Bignoniaceae, Tecomeae). Darwiniana, v. 46, n. 2, p. 304-317, 2008.

MATTOS, J.R. Handroanthus, um novo gênero para os "ipês" do Brasil. Loefgrenia, São Paulo, n. 50 , p. $1-4,1970$.

RECORD, S.J. Woods of storied structure. Tropical woods, n. 76, p. 32-47, 1943.

RECORD, S.J.; HESS, R.W. American timbers of the family Bignoniaceae. Tropical Woods, n. 63, p. 9-38, 1940.

RECORD, S.J.; HESS, R.W. Timbers of the New World. New Haven: Yale University Press, 1943. $640 \mathrm{p}$.

SANDWITH, N. Y. Notes on South American "Bignoniaceae". Lilloa, Tucuman, v. 14, p. 133137, 1948.

SANDWITH, N.Y.; HUNT, D.R. Bignoniáceas. In: REITZ, P.R. Flora Ilustrada Catarinense. Itajaí: Herbário Barbosa Rodrigues, 1974. 172 p.

ZAPATER, M.A.; CALIFANO, L.M.; CASTILLO, E.M. del; QUIROGA, M.A.; LOZANO, E.C. Las especies nativas y exóticas de Tabebuia y Handroanthus (Tecomeae, Bignoniaceae) en Argentina. Darwiniana, v. 47, n. 1, p. 185-220, 2009. 